\title{
LIBERÁNDONOS DE DIOS Y MARX
}

\author{
RELEASE FROM GOD AND MARX
}

\author{
Francisco Tomás González Cabañas \\ (Cámara de Diputados de la Provincia \\ de Corrientes - Argentina)
}

\begin{abstract}
RESUMEN
El marxismo latinoamericano - como respuesta al teocentrismo medieval inoculado por la universidad como claustro del conocimiento - actúa como concepto enquistado en la filosofía política: vendría a ser como el opio de los intelectuales contemporáneos: nos limitamos bajo estas categorías eurocéntricas de Dios y de Marx para comprender la realidad política y filosófica, desde esa inoculación educativa que se realiza a partir de lo filosófico, únicamente entendido como ejercicio disciplinar, asentada no en el logos sino en la vara del pupitre, en la férula de la nota autoritaria, en el mundo formalmente aceptado de lo académico.
\end{abstract}

Palabras claves: marxismo, latinoamericanismo, filosofía política, filosofía de la liberación.

\section{ABSTRACT}

Latin American Marxism, in response to medieval theocentrism inoculated by the university as faculty of knowledge, acts as concept entrenched in political philosophy, would be like the opiate of contemporary intellectuals, under these Eurocentric categories, God and Marx, we limit to understand the political and philosophical reality from the educational inoculation is done from the philosophical, only understood as an exercise discipline, seated, not the logos or philosophical intensity, but the rod of the desk, in the splint of note authoritative in the world formally accepted by academics.

Keywords: Marxism, lationamericanismo, political philosophy, philosophy of liberation.

\section{La posibilidad de una filosofía latinoamericana, af ricana o no europea}

Consideramos que la vinculación —o más convenientemente expresado, el sincretismo- de ambos conceptos (o cualquier otro patronímico o gentilicio) para elucubrar en claustros educativos, la categoría de Filosofía latinoamericana, no es más que un ejercicio literario, poesía académica, un material exquisito - en ciertos casos exótico y en otros, necesario- para reafirmar, contra fácticamente, el dominio conceptual de lo occidental o de su desprendimiento el eurocentrismo, o el latinoamericanismo como mera reacción, que justifica aquello.

Partiendo de una de las aporías más decisivas de la historia de la humanidad, del discernimiento entre lo uno y lo múltiple para el descubrimiento, la interpretación, invención, deconstrucción, o cualquier término por el cual hayan surgido las más diversas corrientes de pensamiento (que no dejan de ser conversaciones concatenadas con el fin de dialogar de manera intergeneracional y correr lo sucedáneo del tiempo) nos encomendamos a la encomiable empresa - jactancia intelectual mediante-, de invalidar la categoría de Filosofía latinoamericana; no solo desde la perspectiva etimológica, histórica y, en definitiva, discursiva sino también desde la lógica del razonamiento, arriba señalado como uno de los puntos neurálgicos del juego de conceptos de las primeras y las últimas causas, validando por ello, las infinitas filosofías que existirían dentro de esa delimitación, como decena de casos puntuales de 
que supuestas subcategorías o no existen en cuanto tales - es decir como formando parte de un categorial que los englobe, que los enmarque (no podría nadie determinar su lazo de vinculación o de pertenencia; nadie que no se pretenda dominante, como por contraposición o reacción, ante ese predominio de la filosofía occidental o filosofía a secas, que per se, refiere a todas desde ese imperialismo intelectual, paradójicamente del que nacería ese gran concepto de filosofía latinoamericana) - o existen en forma múltiple, en todas las manifestaciones que así se pretendan y que mediante el uso de la semántica así lo señalen.

La multiplicidad de filosofías dentro de lo que geográficamente se considera Latinoamérica (como todas las delimitaciones categoriales, surgidas desde los preceptos de la conquista como más luego del sincretismo, violencia mediante) invalida la posibilidad de la unidad pretendida por el alma académica que, obviamente, actúa por instituciones y usinas de poder, generadas desde aquel imperialismo intelectual que se pretende, con la arrogancia del que plantea las reglas de la discursividad, como el único apto para determinar cuáles son los límites del pensamiento, en el caso de que este los tenga, claro está.

Advertir que en verdad estamos en presencia de un fenómeno de perspectiva, de pensamiento (o de como queramos llamar) que pese a ser conquistado no ha dejado de pensar, bajo sus propios términos que, alguna vez, podríamos caer en cuenta de que nuestro occidente en crisis lo precisa, como maná del cielo, pero que para esto debemos prescindir de sus formulismos y - por sobre todo - de sus métodos y rigores, viciados de una significación que obliga al ocultamiento de lo pensable o filosofable que podríamos encontrar fuera de lo europeo u occidental.

La filosofía latinoamericana no debe circunscribirse a aquellas reflexiones que solamente tienen como objeto el mundo cultural, ético, político, religioso, socioeconómico, etc., de los países de esta parte de América, aunque algunos autores con argumentos válidos también así la conciben. Por supuesto que de algún modo tienen que aflorar tales problemas en el ideario de cualquier filósofo de esta región con suficiente dosis de autenticidad. Pero el hecho de que aborde estos temas no le otorga ya licencia de conducción para las vías de la universalidad (Guadarrama, 2008: 3).

Consideramos que más allá de la "necesidad latinoamericana, africana o asiática" de reafirmar sus procesos de pensamiento, sus prioridades y, por qué no con ello, de la revisión de su historia con los elementos condicionares y - por sobre todo - vejatorios, bajo la auto asignación o el bautismo de sus corrientes, es una necesidad eurocéntrica que exista otro que pretenda emular, tomar de suyo o ser parte sin el estigma de víctima, del que siempre - por otro lado, ese "occidente intrusor" - se ha adueñado bajo el término del universalismo.

Finalmente, y como para no adentrarnos en lo que podría significar el momento más intenso, formalmente establecido o nominalizado, en lo concerniente a la Filosofía latinoamericana — que es ni más ni menos, como veremos más adelante, la filosofía de la liberación-, es en el manual de Horacio Cerutti, La filosofía de la liberación latinoamericana en donde lo arriba mencionado se describe como una polémica cruzada y argumentada en textos y ponencia, por parte de Leopoldo Zea y Augusto Salazar Bondy, donde coincidiremos con la siguiente cita:

\footnotetext{
Ajenas a todo fundamentalismo, las fundaciones de la filosofía latinoamericana nos revelan que no se trata de enunciar principios que enclaustren la esencia de Latinoamérica en unas formas exclu yentes, sino de ejercer la razón, en sus múltiples dimensiones intelectuales, emocionales y estéticas, con el fin de comprender pluralistamente nuestro múltiple mundo cultural e histórico, y desde allí avanzar a una relación constructiva con otras civilizaciones. Si como ha señalado acertadamente Guillermo Hoyos, 'filosofia latinoamericana significa uso crítico de la razón', creo que con el mismo derecho podemos enunciar la recíproca y sostener que el uso público de la razón entre nosotros y de cara al diálogo con otras experiencias culturales significa filosofía latinoamericana (Dussel, 2009: 261).
}

Superado el obstáculo terminológico o metodológico para asumir (o no) una denominación acerca de una filosofía "patronímica", a fin de que la misma sea aceptada en los reductos o claustros del saber, descontamos de la necesidad de la misma en un sentido estrictamente político (también veremos más adelante que tanto Hegel como Cerutti hablan, el primero de libertad política para el desarrollo filosófico, y el segundo del desarrollo de la filosofía de la liberación como una filosofía política, 
ambos por el eurocentrismo) sobre todo en los supraorganismos internacionales, que regulan el derecho internacional, público y privado: el "contratismo social" a escala universal por llamarlo de alguna manera.

Neologismos — contradictorios en sí mismos — que surgen para acendrar la necesidad de la existencia de organismos internacionales los cuales planteen la generalidad de lo humano a través de la fundamentación del logos, como razón (valga la redundancia) y el origen de lo jurídico y de lo ético que dan razón de ser a estas instituciones que determinan las razones en que deberíamos entendernos todos los seres humanos. La necesidad, por tanto, de que la explicación o aseveración de las primeras y últimas causas, es decir la Filosofía como concepto y, en su ulterioridad, como piedra basal de imposiciones dialécticas que luego se transforman en imperativos de poder fáctico, existan en lugares como Latinoamérica y África, como condición necesaria para la imposición tanto de modelos de organización social (colectivos, por ende políticos) como de formas de vida (individuales, por ende, existenciales) cuando en verdad en la manifestación — sincretismo violento mediante-, sus expresiones filosóficas (en caso de que las hubiere entendidas desde el categorial de la filosofía del logos "occidentecentrista") surgen de manifestaciones poéticas o artísticas-danzantes. Organismos internacionales que regulan lo político, lo económico-comercial y lo vivencial (salud, expresióncomunicación, etc.), amparados en la Declaración de los Derechos Universales del Hombre y acotados en sus maniobras fácticas o prácticas por tanto que solamente condicionan desde lo teórico o teorético por la autodeterminación de los pueblos, encuentran en el logos occidental, dialógico o que dialoga de un tiempo a esta parte, con el Oriente adormecido o aletargado por el opio de la razón instrumental impuesta por aquel Occidente en los períodos de conquista-, no han resuelto este dilema trascendental que vincula dos continentes, dos expresiones de ser ante el mundo: la latinoamericana y la africana. Si bien son dos procesos disímiles y en estadios diferentes, a través del relato filosófico, de la Filosofía como discurso validante o validador, para que se dispongan supuestos derechos universales que en verdad, jerarquizan la relación entre clases distintas de hombres, que no son como las corrientes europeas de pensamiento nos quisieron hacer entender (dominantes y dominados, opresores y oprimidos) sino más bien, son los que vivencian la existencia, desde los límites del lenguaje, de esa construcción iniciada con los primeros filósofos griegos, a diferencia de quienes lo vivencian desde la expresión poética, fundante de las aseveraciones estipuladas más luego como fundantes, imperantes y condicionadoras.

La noción de universalidad aplicada a lo estricta o particularmente filosófico, se la debemos a Hegel (1970), uno de los alemanes eminentes que sí nos permite la digresión y no puede eludir el haber conformado esa "conciencia alemana" que convalidaría con los votos - años luego- el horror plasmado con el régimen social y político más siniestro de la historia moderna. Su consideración acerca de esa universalidad la anatematiza, al escindir, apartar y colocar en una cámara de gas a regiones enteras del globo, precisamente, a todo un continente. Podríamos extendernos en otros pasajes de la obra mencionada, en donde se realizan apreciaciones antropológicas que orillan claramente lo proverbialmente discriminador y xenófobo; pero es más interesante detenernos en esta construcción teórica de lo universal (desde ya que esta consideración proviene de la herencia inoculada por el poder del claustro, que dispuso que la primera historia de la "ciencia de la verdad" sea el "Libro I" de la Metafísica de Aristóteles. Como sabemos, se podrían seguir escribiendo obras completas del aristotelismo en Hegel, desde la continuidad que hizo el teutón de los principios de tesis y antítesis propuestos por el estagirita como corolario simbólico de la síntesis, complementada por aquel, por ejemplo, que profundiza nuestra autor citado al desterrar las fronteras de lo filosófico también a América: "El nombre de nuevo mundo proviene del hecho de que América y Australia no han sido conocidas hasta hace poco por los europeos[...] este mundo es nuevo no solamente relativamente, sino absolutamente" (Hegel, 1997: 170). Los americanos viven como niños, que se limitan a existir lejos de todo lo que signifique pensamiento y fines elevados. Las debilidades del carácter americano han sido la causa de que se hayan llevado a América negros, para realizar trabajos duros.

Finalmente, y como si le cupiese algún tipo de duda a cómo consideraba la universalidad filosófica, nuestro autor lo deja expresamente narrado: "En Occidente estamos en el verdadero suelo de la 
filosofía; allí tenemos que someter a consideración dos grandes formas, distinguir dos grandes períodos, a saber: 1) la filosofía griega, y 2) la filosofía germánica” (Hegel, 1984: 211).

El mundo americano, que fuera descubierto (en virtud), más por la intervención del azar, la necesidad y los caprichos de la aventura que por los progresos de una ciencia supuestamente siempre en ciernes y que brinda la posibilidad de extender las fronteras de lo humano (podríamos afirmar que un maridaje indisoluble lo constituyen Occidente y la técnica que van a la postre, en una suerte de carrera alocada sin metas precisas, ni mucho menos naturales, sino que se impostan como espejismos que so stienen aquella unión ficta), funda la nueva territorialidad bajo el imperativo categórico de lo educativo y lo político. Debemos nuevamente desandar lo que nos deja la herencia, la tradición o los cánones academicistas y, a su vez, no por ello caer en ese exotismo que esa misma academia tolera o acepta como excepción a la regla y que define como Multiculturalismo. Es decir, no podemos, no debemos poner o citar a un hermano originario, autóctono o primitivo - que, por tradición oral, haya recibido de sus ancestros el ritual que, de acuerdo a sus concepciones del mundo, lo acercaban al hombre con la eternidad, esto sólo sería un apartado menor, en un curso en una facultad europea de Filosofía o Antropología. La verdad, correría por lo que quedó asentado, muchas veces por manos barbáricas (precisamente este término, es una muestra cabal de cómo ha entendido siempre lo europeo lo ajeno y lo propio; bárbaros eran considerados los que habitaban fuera de la Roma imperial, el correrse de ese límite ya los hacía pertenecer a un submundo peyorativo) y casi siempre manchadas de sangre, contaminadas por el hedor de lo peor de la condición humana, o lo que simplemente se entiende, o se trata como historial formal u occidentalmente aceptada.

No podemos apartar la mirada de los procesos de conquista llevados a cabo siglos atrás, en nombre de la razón iluminada por la esperanza de la religiosidad e impulsada a su vez, por la avidez de recursos, de extensión y de expansión en ese mismo sentido "occidental". Sin embargo, no queremos que la circunscripción de la temática nos haga salirnos de nuestro eje, de lo que planteamos más allá de esta cuestión que bien podría ser entendida como meramente historicista.

Independientemente de los millones de litros de sangre derramados, para que desde la pluma podamos expresar esto mismo como una nimiedad en el presente capítulo de lo humano, lo cierto es que deberán ser otros - más allá de los que ya han sido- quienes consignen estos actos despreciables con la vida y con la humanidad, entendida, precisa y paradojalmente, bajo categoriales pura y exclusivamente occidentales, dado que nuestra intencionalidad discurre por dejar en claro que pese a tamaños actos de sujeción, esa misma conquista entronizada en cuerpo y alma mediante violencia ha hecho que dos continentes conquistados puedan ser sometidos filosóficamente. Ambos procesos se encuentran ante un mismo cuadro de situación, el referido y viven desde un inicio reacciones, modos de ser ante el mundo - debido a esa imposición que los modifica desde el encuentro entre las civilizaciones - y respuestas o manifestaciones, de formas muy diferentes.

Para dejar aún más claro el planteo: referimos que, pese a la imposición, a la ocupación y a la dominación en todos los órdenes ocurridos durante siglos, no se ha podido obtener por parte de ese occidente dominador, el alma, el espíritu, la esencia o en el más griego —y por ende occidental— de los conceptos, la ousía de los pueblos latinoamericanos y africanos.

Encontraremos que, por intermedio de lo considerado desde ese occidente centrista, conquistador, modelador o impulsor de referencias obligadas, lo filosófico anida en ambos continentes en expresiones sensoriales o más vinculado a lo emocional que lo tradicional u originario del logos racional (valga la redundancia) tanto en lo poético como en lo festivo y musical; asimismo, encontraremos vinculaciones tanto en lo mitológico como en lo religioso.

Es imperioso afirmar que el proceso de coloniaje, dependencia o el férreo establecimiento del imperativo categórico de pensar como condición sine qua non, bajo la égida o la férula de conceptos eurocentristas, se da por intermedio de los supracategoriales dentro del campo disciplinar y académico de lo filosófico, de "Dios y Marx". Ambas acepciones actúan como inicio o fin y, por ende, inmiscuidas en el desarrollo de los pensamientos o tratamientos del logos o filosofía, sobre todo en 
Latinoamérica. Sin pecar de historicistas, la mitad del ágora latinoamericanista obedece —cual dogma libre de raciocinio - a la existencia-presencia del dios, establecido conceptualmente y bajo rigor espartano por la "compañía de Jesús" más conocida como los jesuitas, quienes extendieron la existencia del todopoderoso más allá de la divinidad, sedimentándolo a lo largo de los siglos de la historia del pensamiento como fuente de toda razón, entronizándolo como motor inmóvil o punto de partida inexcusable para quién se preciara, no ya de católico o cristiano, si no de partícipe de la historia de Occidente; un Occidente proverbialmente europeo, que explicara por el apropiamiento de ese logos o de esa razón lo que necesariamente debería ser creído, por la necesidad incita a asirse a algo que fuera, al menos un poco más que la orfandad, inexplicable y nauseosa (previamente temblorosa) que precisamente, resurge o renace como reacción, histórico-político-dialéctica y por intermedio de un proyecto filosófico-materialista y ateo, por sobre todas las cosas. En relación a la obra de la "compañía de Jesús", analizada desde una perspectiva de poder, refirió Napoleón Bonaparte:

Los Jesuitas son una organización Militar, no una orden religiosa. Su jefe es el general de un ejército, no el mero abad de un monasterio. Y el objetivo de esta organización es Poder - Poder en su más despótico ejercicio - Poder absoluto, universal, Poder para controlar al mundo bajo la voluntad de un sólo hombre (El Papa Negro, Superior General de los Jesuitas) El Jesuitismo es el más absoluto de los despotismo - y, a la vez, es el más grandioso y enorme de los abusos (Recuperado de Infonom.com).

Esta batalla, que bien pudo haberse desatado no ya en una facultad, sino en un aula determinada de la misma (conviniendo o recordando en verdad, que la universitas o el concepto educativo fue instalado también merced de los jesuitas), se libra en los extensos terrenos de los continentes, en donde lo occidental o europeo ya había hecho mella a través del eufemismo del "sincretismo" que en verdad ha sido conquista a sangre y fuego e imposición categórica, que necesariamente repelió cualquier tipo de manifestación dialógica.

Queremos subrayar o no dejar de mencionar un caso específico que bien podría iluminar lo que estamos señalando, en cuanto a cómo sigue operando esa clausura occidental, a cómo ese sometimiento arquetípico (la mayoría de los habitantes del nuevo mundo son descendientes directos de mestizos: productos genéticos del entrecruzamiento entre conquistadores y conquistados) continúa socavando la posibilidad de enfocar lo que ha ocurrido, desde otra óptica o perspectiva.

Para aquellos que, con toda lógica y razón eurocentrista, puedan esgrimir que la vinculación ÁfricaLatinoamérica (al desconocer los millones de litros de sangre derramada y el sistema esclavista que sustentó el modelo económico, político y social de la conquista) es más que forzada, les brindaremos una muestra clara que se produjo en una cultura precolombina, la cual fue arropada por el poder jesuita y esa interpretación que algunos, como Leopoldo Lugones en su obra El imperio Jesuita, caracterizaron como "comunismo teocrático".

Los Guaraníes fueron una cultura (quedan vestigios o reductos de las mismas muy apocados en todo sentido) que habitaron el Litoral argentino y la actual República del Paraguay; el sentido del mal antes de la llegada de los conquistadores - no estaba vinculado a un interpretación religiosa, tal como lo implementaron luego los europeos.

Los guaraníes forman una comunidad de iguales donde principia el altruismo y la distribución de los productos de subsistencia, de acuerdo a las necesidades de cada cual. Así es como se reparten lo producido en las cosechas y lo que obtienen de la caza, de la pesca y de los frutos recolectados (García, 2014: 19).

Escribía el Padre Andrés en sus apuntes y agregaba:

Para ellos no existe la propiedad de la tierra, se la considera un bien común al cual todos tienen la obligación de cultivar y la equidad de repartir los bienes producidos; diferencia fundamental con el sistema de los conquistadores españoles que reclamaban el derecho de la propiedad privada para apropiarse de los espacios que les apetecen y, como no cultivan la tierra con sus propias manos, necesitan de vasallos para que lo hagan; nada mejor-entonces-que utilizar a los indígenas domesticados para estos menesteres (2014:19). 
Existe una figura clave en esta cosmovisión: una suerte de personaje mitológico o legendario llamado "El Pombero", una especie de duende, de conformación física extraña — con pies con dos talones, exageradamente bajo y con un miembro viril desproporcionado-), al que le atribuían embarazos no deseados y actuaba u oficiaba como temor simbólico para los niños o para los que quisieran infligir la ley; por ejemplo, no salir al espacio de fuera de las aldeas en horarios no aceptados (luego del mediodía y antes de la tarde, en la siesta, espacio que actualmente en donde habitaron los Guaraníes, se corta aún hoy, la actividad laboral y comercial y se duerme) lo sorprendente es que esa voz, tal como expresan estudiosos a continuación, posee una base africanista.

Para Marily Morales Segovia se originaría en la voz africana "Pomba" que identifica a un demonio femenino propio de la cultura que trajeron a estas tierras los negros esclavos de África hacia principios del siglo XVIII (Poder Ejecutivo de la Provincia de Corrientes, 1988: 25).

Tampoco queremos sobreabundar de argumentación, pero existen religiones o cultos enteros que reflejan este sincretismo forzado, este sincretismo del dolor, o del sometimiento entre África y Latinoamérica; un ejemplo claro es el "Umbanda" y sus ramificaciones que por obviedad no explayaremos sobre su vinculación entre lo señalado, como condición necesaria y suficiente para lo expresado.

Todos los hijos de aquella circunstancia — generaciones posteriores al latrocinio-, ven y sienten correr en sus venas, la sangre de la sinrazón que no ha dejado víctimas ni victimarios pero que, sin embargo, ha dejado un modelo claro de cómo pensar el mundo y desde qué lugar incluso.

'Si la historia la escriben los vencedores' aseveración atribuida a George Orwell, la frase conceptual se completa con "existe otra historia de los vencidos", tal como si fuese el estandarte de un ejército de vencedores morales, de melancólicos o de románticos revisionistas que, mediante un gran esfuerzo investigativo e intelectual, se empeñan en relatar las modificaciones a esa gran historia oficial, a la que suelen torcer.

Simplemente para cerrar la mención de los guaraníes, lo canónico siempre dio por sentado —o lo transmitió como verdad inexpugnable - que el proceso vivido por esta cultura fue de alguna manera una salvación, una gracia en sus vidas, un hecho fortuito que obedecía en realidad a los indescifrables designios de un dios que lo así lo quiso.

Entre 1537 y 1616 se registraron veinticinco rebeliones de los indios guaraníes contra la invasión de la dominación española. No querer trabajar para los españoles y al mismo tiempo reafirmar sus tradiciones religiosas amenazadas, fueron las dos principales causas. El levantamiento del cacique Oberá en la región de Guarambaré, por el año de 1579 es un caso paradigmático de lo que fueron muchos de los movimientos de liberación Guaraní (Meliá, 1986: 30).

Como podremos ver en la siguiente cita, vamos cumplimentando uno de los preceptos de lo que se da en llamar la Filosofía de la liberación sin que hayamos optado o no por pertenecer o coincidir con la misma; pero de esto se trata precisamente el pensar desde los lugares arquetípicos, el despresurizar de elementos que podrían desnaturalizar nuestro razonamiento, desde el lugar en el mundo en donde, si se quiere, fuimos arrojados.

La filosofía de la liberación, ya iniciada por Mariátegui en sus reflexiones sobre el indigenismo, debe desarrollar un discurso filosófico sobre la naturaleza del amerindio, sobre su pensamiento mítico-racional, sobre su lugar en la historia posterior a la conquista. Como hecho ético debería propugnar por un desagravio histórico del indio americano en 1992: cinco siglos de dominación, genocidio y muerte. Sin embargo, allí están y reclaman sus tierras, su dignidad, su libertad, su autonomía política y cultural. ¿No sería esta una ocasión propicia para avanzar filosóficamente estos temas de la filosofía de la historia americana? (Dussel, Siglo XXI, s.f.).

Claro que la espada y el crucifijo solo podían hacer una parte; la razón instrumental debía seguir sirviéndose del pupitre, del sistema de control que disponía lo educativo, para luego generar trabajadores en serie, al darles un sentido técnico, de progreso, de interpretación del mundo, de finalidad burda y absurda, que no es ni más ni menos que la "occidentalidad brutal" y 
empequeñecedora de la cuestión humana, que dinamita el alma y amputa el espíritu y ocultadora del ser. El círculo hermético por donde hacían transitar ese conocimiento, esa piedra filosofal entendida como tesoro escondido o a esconderse o a develar (esto es muy medieval y se puede observar claramente en textos llevados al séptimo arte, hablamos de En el nombre de la rosa de Umberto Eco) fue necesariamente el ámbito de esos claustros que, desde la definición misma, establecía que el ingreso no era solamente para el que deseara, sino que se constituía en un riguroso círculo cerrado en donde la circulación de ese conocimiento —o de ese logos occidental — estaba al alcance de muy pocos, los que cumplieran las prerrogativas disciplinares de obediencia debida y rigor metodológico. Daremos un ejemplo de cómo la tradición surge de Aristóteles: "El tema que desde hace mucho tiempo, ahora y siempre, se ha buscado y ha planteado renovadas dificultades, ¿Qué es el ente?, viene a ser, ¿Qué es la ousía?" (Aristóteles, 1986: 285). Luego generará un rigor mortis en cuanto a la posibilidad de entender de qué se trata, sin que se pueda salir de un camino, enfatizado y determinado casi fanáticamente, por un conjunto de reglas, o un corset o molde que impida el poder generar perspectivas más allá de lo estipulado por quienes se creyeron — de un momento a otro- los únicos capaces de establecer las reglas de juego del conocimiento; como si al abordar el mismo los debiera tener, más aún en forma expresa y específica, como estos, enajenados de libertad, así lo dispusieron.

Nunca dejará de pasar tal estadio y, probablemente, no se le brinde ningún tipo de consideración academicista a lo no aceptado o a lo que al menos pretenda situarlo dentro del ámbito de lo admisible. De hecho, como observamos, lo que no proviene de la tradición o de lo metodológicamente comprobado, le puede llegar a corresponder el exotismo de lo "multicultural" o, a lo sumo raro, acepciones que nada se corresponden con la seriedad occidental.

Preguntamos ¿Qué significa la seriedad del intelectual? ¿Está dada sólo por un riguroso aparato crítico y abundantes citas en lenguaje original? La única seriedad que queremos y buscamos porque no tenemos es la del compromiso con el hombre latinoamericano con su ser y su verdad (Cerrutti 2005: 299).

A esto es lo que reacciona o lo que en verdad se gesta ante tanta predeterminación o arbitrariedad, en un ámbito en donde supuestamente se pregonaría lo contrario, tal como el claustro universitario. La institución de características perversas, al alentar vientos libertinos que no dejaba circular dentro de sus propios edificios de estilos medievales, se vio asediada por la necesidad de una mayor apertura; el aumento de población y los cambios de paradigma, que a nivel político-filosófico se coronan con la llegada del Marxismo, como antídoto, como reacción, como mecanismo de defensa, ante la asolación de la hiperpresencia de un dios que, en verdad, estaba por fuera de la universidad.

El Marxismo irrumpe, además, como el espacio de esa libertad faltante, pero apuntando esa ausencia libertaria de las fábricas desde el núcleo básico del sistema económico y político: se auto enviste de solución salvífica, pero desde el presidio de máxima seguridad del claustro. La única forma de que esto precisamente no se notara, que siguiera oculto, era que precisamente naciera como dogma que apuntara a la realización de las libertades (podríamos volver a Hegel, cuando estipula que lo filosófico solo puede darse en el ámbito de la libertad política; de todas maneras, es una obviedad crasa que toda la historia sea nada más que el diálogo intergeneracional entre un puñado de hombres europeos, avalado, promocionado y sostenido por otro grupo un poco más cuantioso de seguidores o aduladores) posibilitándole a ese proletario librarse de las esposas del sistema productivo. Claro que esta formulación, originada en ese laboratorio con cláusulas aún más atentatorias de las libertades más básicas, nunca sería vista desde esta perspectiva. Ese dispositivo de encapsular lo que pueda ser dicho y entendido como verdad, debía salir de algún presidio, por más que discutiera otros sitios de encerramiento de la libertad.

El traslado al ámbito intelectual latinoamericano de algunas de las polémicas que desde los años cuarenta y cincuenta se venían produciendo en el seno del llamado "marxismo occidental"-contrapuesto al marxismo-leninismo emanado del bloque soviético - sobre algunos temas filosóficos, éticos y estéticos, conmovieron cada vez más el ambiente en el que se desarrollaría el marxismo en América Latina. Por otra parte, el auge que tomaron las posiciones filosóficas críticas del marxismo en diverso grado, unas veces para tratar de permearlo como el existencialismo sartriano y otras para sustituirlo como la filosofía de corte neopositivista, la analítica, el neotomismo, etc., dieron lugar a que el marxismo se situara en mayor medida en el centro del debate intelectual y se expresase de diversas formas como en el caso de su 
interpretación como filosofía de la praxis desarrollada por el destacado pensador hispano-mexicano Adolfo Sánchez Vázquez (Guadarrama 2008: 35).

El terreno por sobre seguro, por más que sean senderos de bosque, debe atenerse necesariamente, para sus consideraciones, sus finalidades hipostasiadas, a lo escrito, a lo académicamente aceptado; jamás puede estar navegando en un éter no comprobado como una tradición oral, en lo indeterminado de una danza, de un ritual, de un contemplar un amanecer, consustanciado en el ser ahí, desde lo que se es, con la Pachamama o con la madre naturaleza. De allí la necesidad que tuvimos en traer a colación la hipótesis del posible diálogo platónico no comprobado, la necesidad de verdad, de esa verdad ciencista occidental (que nunca pudo arrojar ni un ápice de luz ante el fenómeno más trascendental de lo humano, que es: ¿qué ocurre y por qué ocurre la finitud o la muerte?) no tolera, no acepta, no asimila, no absorbe nada que no sea tal como dispusieron sus reglas antediluvianas.

África y Latinoamérica, sin embargo, colonizados y conquistados por ese occidente reglado y reglamentador, no solo que vieron imposibilitadas sus posibilidades de que se conocieran las distintas formas de relacionarse con las primeras y últimas cuestiones de lo humano, si no que tuvieron que deconstruir, decodificar lo impuesto, asimilarlo y reconvertirlo a su interpretación y, con ello, reescribir lo que se les había dado o impuesto como lo que debiera ser. Como podremos observar, se dio y, como decíamos, por intermedio de una reescritura o resignificación de ese concepto tutelador europeizante, se tradujo en nuestras tierras como, revoluciones atestadas de armas y de violencia, pero que paradojalmente siempre recurrieron, tanto en unos como otros (es decir los que estaban a favor y los que estaban en contra) a los sectores más desposeídos, marginales y pobres.

Quien llama a los pueblos africanos "no desarrollados" o "subdesarrollados" emplea una terminología eurocéntrica la cual el africano mismo no es capaz de comprender. Un africano no planifica el futuro y no porque sea particularmente pusilánime ante la realidad por venir, sino porque no concibe que el tiempo tenga esa medida. El centro de atracción de la medición del tiempo es el Zamani, en donde pululan cantidad de mitos explicativos del origen del mundo, del ser humano, del silencio de los dioses ante el hombre, de la llegada de los humanos a la tierra de los antepasados. El sentido yace en el Zamani.

Como observamos a continuación, las problemáticas — más allá incluso de las barreras idiomáticas y geográficas (recordamos de todas maneras que de acuerdo al proceso conocido como "Pangea", hubo un tiempo en que África y América del sur formaban parte del mismo bloque continental) — no dejan de ser similares, sincréticas, independientemente incluso de aspectos etnográficos e históricos. Si bien ambos continentes formaron parte de un proceso que los tuvo por igual como víctimas ante la irrupción y la dominación perpetrada por la razón iluminada, por los hijos o alumnos de la filosofía universal. Lo cierto es que existen ciudades populosas que, históricamente han sido sincréticas (por ejemplo, la primera capital del Brasil, San Salvador de Bahía) y que desde aquellos años de fustigación, propone en esa convivencia, en ese maridaje o consustanciación entre lo africano y lo americano, fenómenos o expresiones culturales que trasciendan lo meramente artístico (ya expresamos la religiosidad, el carnaval, la danza-ritual de la capoeira, o el olodum, como ya manifiesto filosófico aglutinante del orgullo de ser).

Fanón, desde el ángulo de la dependencia africana se plantea el problema de la dependencia y el de su necesaria correlación el de la liberación de los pueblos bajo colonización. Planteamiento que transforma la vieja preocupación universal, por lo que se refiere a hombres y pueblos que han entrado en la historia bajo el signo de la dominación colonial. Así lo reconoce ahora el pensamiento, o filosofía, de la liberación, que se hace simultáneamente expresa en nuestros días en América Latina, Asia y África (Zea Aguilar s.f: 209).

Como expresáramos, de lo que se trata — en el fondo - es de volver a definir de qué se trata o qué es lo que trata o debería tratar la filosofía. La definición conceptual de filosofía ha sido inquietud de diversos filósofos a lo largo de la historia, dejando como resultado innumerables concepciones en diferentes contextos y épocas. Cada concepción permite darle un enfoque de acuerdo a la definición que se tenga; no existe una respuesta única y una definición exacta de lo que es la Filosofía: cada 
filósofo la caracteriza de acuerdo a sus presupuestos teóricos; es por ello que uno de los principales debates y discusiones tradicionales del ámbito filosófico es su definición. Es pertinente dedicar un espacio para conceptualizar el término filosofía. Para el presente trabajo se asume la perspectiva de que:

La filosofia es el arte de formar, de inventar, de fabricar conceptos [...] crear conceptos siempre nuevos, tal es el objeto de la filosofía. El concepto remite al filósofo como aquel que lo tiene en potencia, o que tiene su poder a su competencia, porque tiene que ser creado (Deleuze y Guattari, 1993: 8).

La filosofía como creación de conceptos busca encontrar nuevas maneras de pensar que conducen a nuevas maneras de relacionarse; ver, entender y escuchar el mundo. Con ello se generan encuentros para vivir otras experiencias. La creación de conceptos permite la crítica y al mismo tiempo la creatividad, es decir:

Los filósofos se pueden clasificar en edificadores (creadores) y sísmicos (críticos); en los dos casos los conceptos se convierten en movimiento y vehiculizan la creación y la crítica; la creación deviene de la crítica y la crítica deviene de la creación (Pulido Cortés, 2009: 96).

La creación de conceptos se convierte en una nueva posibilidad, un acto particular y no una designación que limita la sensibilidad y la experiencia propia, no es un concepto dado ni tampoco se impone, es el reflejo de un acontecimiento. "Los conceptos no nos están esperando hechos y acabados, como cuerpos celestes. No hay firmamento para los conceptos. Hay que inventarlos, fabricarlos o más bien crearlos, y nada serían sin la firma de quienes los crean" (Deleuze y Guattari, 1993: 11).

El concepto no está hecho, es una invención del filósofo que se conecta con la realidad a través de una experiencia que convierte los conceptos en temporales y no en universales; es así como los conceptos no son dogmáticos, ni imposiciones. "La Filosofía se encuentra con la creación, pues este encuentro permite construir nuevos pensamientos que fabrican el concepto para repensar constantemente los acontecimientos del mundo" (Mariño Díaz, 2012).

Inveterada costumbre - como contradictoria y de resultados inciertos - la de poner, establecer, fijar y/o determinar el comienzo, el inicio, el punto de partida de la filosofía tal como la venimos entendiendo desde ese contacto inmemorial del tiempo. Aporías que se bifurcan en senderos sinuosos, de los que nos resulta imposible apartar nuestras pisadas, fijamos en esta exploración el adentrarnos en la perspectiva, en el camino - sino recurrido o recurrente - de lo poético como disparador, como punto cero, agregándole la exhaustividad, probablemente irreverente de considerar el texto homérico: el primer verso de la Ilíada, como ese instante perpetuo, esa perpetuidad capturada a la luz de lo que consideramos inteligible, filosóficamente aceptable, el dial de la sintonía para este largo (como pretenciosamente sempiterno) diálogo que establecimos, con el renunciamiento expreso a una conclusión o a elementos concluyentes, pero del que no podemos o no podríamos renunciar a fijar un principio determinado, específico, que combate ante el desparpajo omnisciente de la incertidumbre del arrojo existencial del que somos parte. Por ende, al dinamitar ese principio formal, forzado y metodológico y poder situarlo en la poética homérica, ¿cómo no podemos ubicarlo en la poesía o en la danza africana? ¿Quién y bajo qué vara filosófica — entendida, esta, como lo argumentado — podrá decir que no es lo que constituye una filosofía menor en relación a otra, que solo varía en diferentes concatenaciones de palabras?

Los elementos fundamentales de la función profética parecen ser los mismos en todas partes. En cualquier sitio el don de la poesía es inseparable de la inspiración divina. En todas partes la inspiración lleva consigo conocimiento - del pasado en forma de historia y genealogía; o de lo que no sabemos del presente, comúnmente en forma de información científica, o del futuro, en forma de profecías en sentido estricto. Su conocimiento siempre se acompaña con música, vocal o instrumental. La música en todas partes del medio de comunicación con los espíritus. Invariablemente encontramos que el poeta y vidente atribuye a su inspiración al contacto con poderes sobrenaturales y cuando lanza sus profecías, su ánimo se ve exaltado y se aleja del que tiene en su existencia normal. Generalmente encontramos en todas partes un procedimiento reconocido por el medio del cual se provoca el estado profético cuando se desea. Las elevadas pretensiones del poeta y vidente se admiten universalmente, y el mismo alcanza una posición social privilegiada donde quiera que se encuentre (Conford, 1987: 120). 
Ese amanecer intelectual de un occidente en donde atardece por necesidad, sedimentó el giro eurocéntrico, pues en Latinoamérica (como espacio no geográfico, más bien conceptual en donde abrevó el continente africano, por el tráfico de esclavos) la reacción ante esa opresión —enmascarada en el dios de quienes impusieron las reglas, sociales, educativas, morales, y religiosas - se dio, necesaria e imperiosamente, por intermedio del marxismo.

Dos casos resultan paradigmáticos. Uno sucedió en Perú, cuando el licenciado en filosofía Abimael Guzmán decidió - inspirado en el fundador del comunismo en su país, el intelectual José Carlos Mariátegui- crear un "sendero luminoso", que no era más que un giro literario invertido, el cual utilizaba el amauta, para señalar que su país debía seguir la luz del camino marxista. No casualmente, el llamado forjador de la peruanidad, exclama lo siguiente, al parecer defendiéndose de lo que pareciera una acusación de eurocéntrico:

No faltan quienes me suponen-replica Mariátegui-un europeizante, ajeno a los hechos y a las cuestiones de mi país. Que mi obra se encargue de justificarme, contra esta barata e interesada conjetura. He hecho en Europa mi mejor aprendizaje. Y creo que no hay salvación para Indo-América sin la ciencia y el pensamiento europeos u occidentales. Sarmiento que es todavía uno de los creadores de la argentinidad, fue en su época un europeizante. No encontró mejor modo de ser argentino (Mariátegui, 2013).

No continuaremos la búsqueda imposible de razones en la sinrazón terrorista que dejó un luctuoso saldo de decenas de miles de muertos en nombre del "sendero luminoso", pero sí es necesario volver a consignar que, tanto el hacedor de esta organización delictiva como su involuntario inspirador José Mariátegui, se reconocían (Guzmán incluso se autoproclamaba "la cuarta espada del marxismo") como marxistas al punto de, uno, ser el fundador de la expresión política del mismo y el otro, su expresión en el hacer de la "revolución proletaria", en la latinoamericana república del Perú donde les toco nacer y decidieron vivir y hacer vivir a sus compatriotas.

Años después, brota de las mismas tierras latinoamericanas — esta vez algo más al norte, en Méxicoun nuevo fenómeno vinculado con la filosofía académica pero que necesariamente (como en el caso de Perú) se disrumpe, se discontinúa, se sale de aquel concepto profundamente eurocéntrico — tanto de forma como de fondo - de congeniar o ensamblar, el rigor metodológico que conlleva a enclaustrar la verdad, como lo hicieron en forma plena en el medioevo y el monopolio ejercido en ambos lugares del poder educativo (educadores y educandos) desde el entronizado concepto, ya movimiento ideológico del marxismo. El "brote" mexicano se denominó la Insurgencia Zapatista y, años luego, sabríamos que el líder Rafael Guillén, pertenecía a las filas filosóficas de la universitas y si bien siempre dejó en claro no ser marxista, no tuvo eco en preconizar que no se lo catalogara de tal manera (más que nada para la prensa) con la diferencia - sobre con todo con Guzmán- que las propias producciones escritas de Guillén, indudablemente profusas le valen una chance, una posibilidad de salirse de esa etiqueta autonómica, asequible a todo aquel que con el solo hecho de plantear aspectos diferentes a lo establecido es indefectiblemente catalogado como un hijo dilecto de la filas del marxismo.

Como expresábamos en relación a Guillén, podríamos afirmar que toda su obra escrita no solo es una justificación a su "polémico hacer", o su posición en el mundo, sino que también es un tratado completo para no ser considerado, catalogado o etiquetado como marxista, pero para ello inevitable o indefectiblemente, sus considerandos han abrevado — en mayor o en menor medida - en el marxismo o neo-marxismo.

Una de las falacias neoliberales consiste en decir que el crecimiento económico de las empresas trae aparejados un mejor reparto de la riqueza y un crecimiento del empleo. Pero no es así. De la misma forma en que el crecimiento del poder político de un rey no trae como consecuencia un crecimiento del poder político de los súbditos (antes al contrario), el absolutismo del capital financiero no mejora la distribución de la riqueza ni provoca mayor trabajo para la sociedad. Pobreza, desempleo y precariedad del trabajo son sus consecuencias estructurales (http://www.cgt.es).

Por supuesto que hemos citado estos ejemplos, sin hacer hincapié ni historicismo, en los procesos políticos (sustentados ideológicamente en lo que se dio en llamar "El marxismo") que se dieron tanto en Latinoamérica como en África durante el proceso mundial conocido como Guerra fría pues, sin 
ánimo de equivocarnos, probablemente estaríamos en un porcentual muy alto de vinculación, al determinar que el concepto del marxismo, como respuesta al teocentrismo, se dio desde el ámbito de la academia, que por veleidades romántico-revolucionarias (recordar en aquellas décadas los conceptos del compromiso intelectual y de los reduccionismos como ideas movilizadoras: "Pidamos lo imposible" como consigna insignia) y derraparon en procesos políticos de facto, pero que surgen como un planteo educativo formal que se elucubran desde las usinas de poder universitarias.

Para ponerlo en términos más claros: el erario público, que sostiene cada una de las universidades de estas partes del mundo, deja de estar presente en otros ámbitos, tan o más necesarios para la mayoría de estos pueblos; es decir, el pupitre de la universidad y el pizarrón significan y representan una anestesia menos en un hospital, una puerta menos en una casa para una familia indigente. La concepción errónea desde la que se parte, la asumimos tanto en el pupitre universitario, como en el espacio público. Vana y absurdamente quiénes siguen mirando a Europa, dando las espaldas a su propia tierra, son los que se erigen en doctos vanguardistas que postulan categorías como democracias agonales o populismos y exacerban aquello que nunca ha sido nuestro; ni deísmo, ni marxismo, ni neomarxismo, ni derechas ni izquierdas. Desde el contrato social, la propia definición de América Latina, los principios de revolución, de libertad, de igualdad y de fraternidad, pasando por todas las constituciones y códigos normativos que se inspiraron en sus legalidades, hasta los postulados de sus intelectuales que han sido - y lo siguen siendo - obcecada y dogmáticamente seguidos por la patria académica-intelectual, el insoportable sopor de seguir siendo tutelados por la razón iluminada francesa, imposibilita que razonemos desde nuestras propias perspectivas, desde nuestras realidades, tanto las profundas, como las superficiales. No es fácil ni sencillo, pensar desde nuestras categorías, de hecho, existe toda una corriente filosófica que lo viene realizando con aplomados pasos a los que no necesariamente debemos seguir como si se tratase de una verdad reveladora, de una autoridad intelectual gestada o propalada en el ámbito académico para imponer una verdad absoluta, en nombre de los sufrimientos de quiénes padecieron imposiciones y no pudieron dar su voz.

Sin querer significar otra cosa de lo que afirmamos, simplemente queremos preguntarnos y preguntar. ¿Cómo le ha devuelto la Filosofía esta inversión a su comunidad? ¿Le ha brindado acaso un sistema político, educativo y/o social nuevos? ¿Ha fomentado cierto onanismo intelectual, en donde —en el mejor de los casos, como subproducto o como resultante - haya brindado tanto a su propia comunidad como a la internacional, no solo decenas de miles de tesis doctorales que duermen el sueño de los justos en libros que nadie lee, sino también doctores que colonizados en sus conceptos eurocentristas no colaboran o contribuyen para que pueda darse la posibilidad de que desde las aulas o fuera de ellas pensemos en términos más relacionados con nuestras características y peculiaridades culturales?

La respuesta la brinda lo que se da en llamar Filosofía de la liberación que, no casualmente, se desdobla en una teología de la liberación donde lo central y fundante es tal como expresara Cerruti mediante Dussel - (actores principales y fundantes de lo filosófico en Latinoamérica) en la opción por los pobres, en una vinculación con el hábitat, con lo dado, con lo originario, no solo no invasivo e integrador y consustanciado en individuo y comunidad sino, también, libre de finalidades para las cuales haya que respetar, a rajatabla, procedimientos metodológicos, estrictos y cercenatorios del sentido más profundo de la libertad.

Lo que puede significar un pensar que entendamos nosotros mismos como latinoamericano, converge necesariamente en los conceptos arriba mencionados, pero interpretados necesaria y básicamente, como la opción por los pobres: por aquel cuya ausencia de algo básico, percude su condición de humano, es la síntesis, (para que los eurocéntricos nos entiendan, en términos hegelianos si lo desean), la abreviatura; es la simbiosis de lo que fue entendido - o mejor dicho impuesto- bajo los términos nominalizados como Dios y Marx.

La dictadura del proletariado, la plusvalía, el sentido de culpa y el paraíso celestial no deben ser playas en donde debamos llevar el barco de nuestros pensamientos; hace tiempo que nuestros pasajeros nos vienen indicando de la no existencia de puertos posibles, en tal eterno transitar. No son pocos los desafíos que recurrentemente se nos presentan en altamar, pero ninguno de los mismos lo 
resolveremos dirigiendo el navío a lugares inexistentes en nuestras latitudes y, por ende, ninguna de las cartas de navegación editadas en aquel occidente tutelador nos puede resultar decisivamente necesario, útil o mucho menos indispensable.

En Latinoamérica, esa profunda, descontaminada de la egida eurocéntrica, se filosofa, es decir se vive en armonía con el logos, al modo semejante que en África, donde el vínculo es mediante la danza (Kaumbaaa), los conceptos de Dios y Marx, no tienen nombres o en el caso de que los tengan no son usados para dominar o controlar como en las usinas de poder intelectual que Occidente llama universidades. Pensar a Dios y a Marx, como algo más allá de su vinculación con el otorgar respuestas al condicionamiento del pobre es seguir sujeto a las imposiciones que esos conceptos nos traen o los que nos vienen arropados o contaminados de un eurocentrismo, del cual debemos necesariamente salir o del cual debemos desintoxicarnos, sin que ello signifique atacarlo o negarlo.

Finalmente, y dado que el ejercicio ensayístico y de presentaciones en Congresos y Universidades que cumplen - en espíritu - el mandato proverbial de lo educativo entendido como lo dispusieron los Jesuitas o escolásticos, citamos a un filósofo europeo, muy en boga en la actualidad, con quien suscribimos en lo siguiente, explicando sin dobleces, el porqué de haber llegado a la situación actual en nuestra intensidad latinoamericana, de la búsqueda de nuestros impedimentos filosóficos propios.

\begin{abstract}
Occidente no tiende a trasladar hacia el Este o hacia el sur una cultura positiva propia, sino a disolver las demás culturas para suplantarlas con un exponente de mera negatividad, es decir, la producción generalizada de su propia figura vacía [.] Occidente no quiere, no sabe, no puede encontrar lo otro sin simultáneamente someterlo a su propio dominio (Espósito, 2012: 264).
\end{abstract}

Es necesaria una perspectiva histórica y antropológica que ilustre, en la larga duración, las interconexiones globales en el interior de América Latina y las comunidades europeas, africanas y asiáticas. Poniendo el énfasis en la multiplicación, diferenciación y complejidad de las interconexiones globales y en cómo adoptaron diferentes formas históricas entre los siglos XVI y XX, tal vez podamos escapar del callejón sin salida epistemológico posmoderno, o de historias que con distintos lenguajes vuelven a reescribir la relación de un centro y sus periferias. Es en este sentido que la historia de América Latina puede ser reevaluada a la luz de sus interdependencias e influjos recíprocos de lo local y lo global, y donde categorías como poscolonial, ciudadanía, nacionalismo o Estado-nación se entrelacen con un proceso abierto al resto del mundo, con una historia hemisférica común que escape a los límites de las fronteras nacionales (Sandoval, 2010: 13).

No abonamos en el latinoamericanismo historicista, como una suerte de contrainsurgencia, como mecanismo de defensa, como la respuesta artera de quién se ubica en el otro eslabón de la también eurocéntrica lógica del amo y del esclavo. Es decir, los profesores eurocentristas o los artistas eurocéntricos, que se extasían cuando pronuncian con la nariz arrugada términos como "diferrance" o hacen largos ensayos con acepciones como proletarios, rizoma o biopolítica, deben continuar su exitoso peregrinar en la vida que suponen han escogido, pero sus cucardas académicas no los habilita a que nos digan, como si fuesen la expresividad unívoca de la Pachamama, qué tipo de procesos políticos estamos viviendo, y mucho menos que nos digan, qué, cómo y a quiénes tenemos que votar, bajo la argucia eurocentrista, de la construcción de un nuevo sujeto histórico que nos liberará de nuestras sujeciones, contradicciones y temeridades. Tomamos sí la semántica del latinoamericanismo para establecer un piso común de entendimiento, para no caer en una suerte de babelismo en donde no nos podríamos siquiera comprender en la significación de enunciados básicos. Podríamos establecer hasta el método — como lo ha creado la institucionalidad forjada del latinoamericanismo analécticocomo para brindar nuestras consideraciones; sin embargo, lo volvemos a subrayar, tal consideración nos ha posibilitado el despertar de pensar desde nuestras categorías, pero el continuar tutelados por otras corrientes que impongan, por más que sean cuestiones propias, tampoco nos parece liberador. Tal vez siquiera creamos en tal término. El no dar sentido, el no sentirnos bajo esa dialéctica del amo y esclavo, nos posibilita aquello que se expresa en ciertos movimientos territoriales que bajo categoriales academicistas pueden ser tildados de indigenistas o precolombinos; sin embargo, para nosotros puede resultar como lo pretendido. Para este texto, para esta circunstancia y para todas. Que en un mundo quepan todos los mundos. Esta es la definición por antonomasia de lo que consideramos 
latinoamericanismo, independientemente cuánto tenga que ver con la versión histórica o, paradojalmente, instituida del movimiento de cuya semántica nos sentimos parte.

\section{Referencias Bibliográficas}

ARISTÓTELES. (1986) Libro VII, Metafísica. Buenos Aires: Editorial Sudamericana.

BARTOMEU Meliá, (1986). “Cap. Oberá”, En Una repuesta profética contra la opresión colonial. pp. $30-40$.

---, (1986) El guaraní conquistado y reducido. Asunción: CEADUC. Pp. 30-40.

CERUTTI, H. (2005) La filosofía de la liberación latinoamericana. México, Fondo de cultura económica.

DUSSEL, E. Mendieta, E. \& BOHÓRQUEZ, Carmen. (2009). El pensamiento filosófico latinoamericano, del Caribe y "latino": historia, corrientes, temas y filósofos. México: Siglo XXI.

---, (s.f.). Para una ética de la liberación latinoamericana. México, Siglo XXI.

---, (s.f.) Retos Actuales A La Filosofía De La Liberación. Recuperado de: http://www.olimon.org/uan/retos-dussel.pdf

DELEUZE, G. y GUATTARI, F. (1993) ¿Qué es Filosofía? Barcelona: Anagrama

ECO, U. (s.f.). En el nombre de la rosa. S/D, Lumen.

ESPÓSITO, R. (2012). Diez pensamientos acerca de la política. Buenos Aires: Fondo de cultura económica. Pp. 264-268

F.M. CONFORD (1987) Principium sapientiae. Los orígenes del pensamiento filosófico griego. España: La balsa de la medusa. Pp. 120-123

GARCÍA, R. (2014). Misiones la república utópica de los jesuitas. S/D, Editorial La Impresión

GUADARRAMA González, P. (2008) "La conflictiva existencia de la filosofía latinoamericana". Recuperado de:http://www.revistadefilosofia.org [consultado el 15 de marzo de 2015].

HEGEL, G. (1970a). Filosofía de la Historia. (Brunstädt). Barcelona: Ediciones Zeus.

---,. (1984b). Introducción a la historia de la filosofía (Primera parte de las Vorlesungen über die Geschichte der Philosophie). Buenos Aires: Aguilar.

---, (1997c) Lecciones sobre la filosofía de la historia universal. Tomo I. Barcelona: Ediciones Altaya.

MARIÁTEGUI, José Carlos (2007) Siete ensayos de interpretación de la realidad peruana Caracas: Fundación Biblioteca Ayacucho

MARIÑO Díaz, Liliana (2012) "La educación filosófica como experiencia y posibilidad", En Praxis \& Saber, Colombia, S/D

Poder Ejecutivo de la Provincia de Corrientes. (1988). El pombero un héroe moderno. S/D

ROUILLON Duarte, G. (2013) Mariátegui, suscitador de peruanidad. Perú: Fondo Editorial de la UMNSM. 
SANDOVAL, Pablo (2010) Repensando la subalternidad Lima: Envión

SUBCOMANDANTE MARCOS (s.f). "Siete piezas sueltas del rompecabezas mundial". [Artículo digital] Recuperado de: http://www.cgt.es [consultado el 24 de marzo de 2015].

ZEA, L, (s.f.). La filosofía actual en América Latina. S/D 